$\frac{10}{3}-3.95$ \&SD
SANDIA REPORT

SAND94-8508 - UC-406

Unlimited Release

Printed February 1995

\title{
A Compatibility Study of Containment Materials in FEFO, Bis-(2-Fluoro-2,2- Dinitroethyl) Formal
}

T. J. Shepodd, S. H. Goods, W. E. Moddeman, P. Foster

Prepared by
Sandia National Laboratories
Albuquerque, New Mexico 87185 and Livermore, California 94551
for the United States Department of Energy

under Contract DE-AC04-94AL85000

Approved for Public Release; Distribution is Unlimited. 
Issued by Sandia National Laboratories, operated for the United States Department of Energy by Sandia Corporation.

NOTICE: This report was prepared as an account of work sponsored by an agency of the United States Government. Neither the United States Government nor any agency thereof, nor any of their employees, nor any of the contractors, subcontractors, or their employees, makes any warranty, express or implied, or assumes any legal liability or responsibility for the accuracy, completeness, or usefulness of any information, apparatus, product, or process disclosed, or represents that its use would not infringe privately owned rights. Reference herein to any specific commercial product, process, or service by trade name, trademark, manufacturer, or otherwise, does not necessarily constitute or imply its endorsement, recommendation, or favoring by the United States Government, any agency thereof or any of their contractors or subconractors. The views and opinions expressed herein do not necessarily state or reflect those of the United States Government, any agency thereof or any of their contractors or subcontractors.

This report has been reproduced from the best available copy.

Available to DOE and DOE contractors from:

Office of Scientific and Technical Information

P. O. Box 62

Oak Ridge, TN 37831

Prices available from (615) 576-8401, FTS 626-8401

Available to the public from:

National Technical Information Service

U.S. Department of Commerce

5285 Port Royal Rd.

Springfield, VA 22161 


\section{DISCLAIMER}

Portions of this document may be illegible in electronic image products. Images are produced from the best available original document. 
SAND94-8508

UC-406

Unlimited Release

Printed February 1995

\title{
A Compatibility Study Of Containment Materials In FEFO, Bis-(2-Fluoro-2,2-Dinitroethyl) Formal
}

\author{
T. J. Shepodd \\ Materials Development \& Diagnostics Department \\ S. H. Goods \\ Engineered Materials \& Processes Department \\ Sandia National Laboratories/California \\ W. E. Moddeman and P. Foster \\ Mason \& Hanger-Silas Mason Company/Pantex
}

\begin{abstract}
We report on a program to evaluate the compatibility of energetic fluids with candidate containment materials. The energetic fluids are constituents of various extrudable explosives developed by Lawrence Livermore National Laboratory. These paste-like explosives consist of explosive particulates (HMX, TATB for example) suspended in mixtures of energetic liquids and are designed to remain extrudable over a wide temperature range for many years. It is important to preclude or minimize interactions between the constituents of the paste and the containment materials since such interactions could result in decreased reliability or failure of the containment vessel as well as intrinsic changes in the flow or explosive characteristics of the paste.

In this report we focus on one specific paste formulation: RX-52-AE (Transferable Insensitive Explosive, TIE), composed principally of the solid explosive TATB and the energetic liquid, FEFO. Compatibility between a number of organic and metallic materials with neat FEFO has been evaluated. The 300 series stainless steels, Al 6061-T6, and Monel 400 showed evidence of surface attack (oxidation or pitting). Polished gold coupons became discolored and XPS analysis revealed the formation gold cyanide. Platinum, iridium, titanium, tantalum and Ta-10\% W showed little evidence of reaction.
\end{abstract}

Among the organic materials, the per-fluorinated materials showed only slight interaction with the FEFO while the polyethylene, polyester and $\mathrm{Aclar}^{\circledR}$ materials were attacked by the liquid. These interactions were manifested in changes in color, net weight gain and mechanical properties. The changes were exaggerated by higher temperatures.

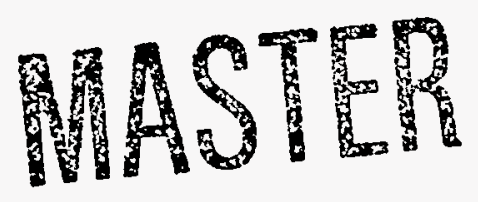




\section{ACKNOWLEDGMENT}

We would like to thank: William Yoshimoto, George Buffleben, Bernie Bernal (SNL), Melissa Dodge, Billie Sims, Tim Quinlin, and Clifford Schaffer (Pantex) for their individual contributions to this effort. 


\section{TABLE OF CONTENTS}

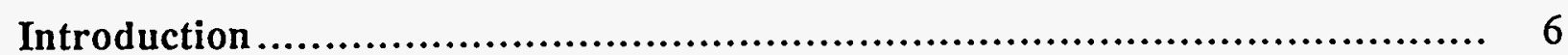

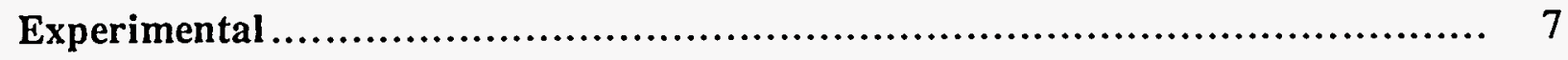

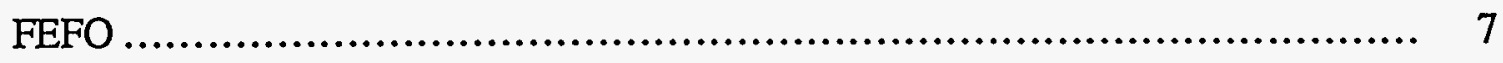

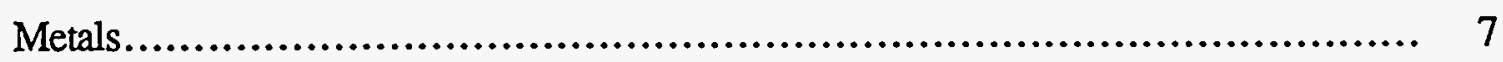

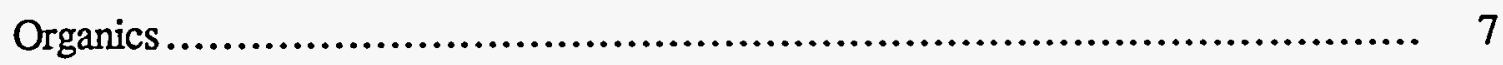

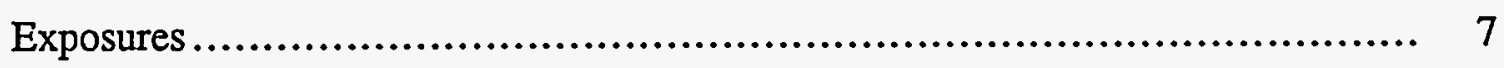

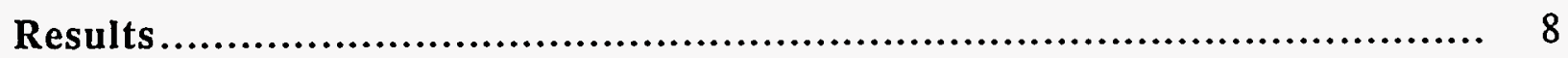

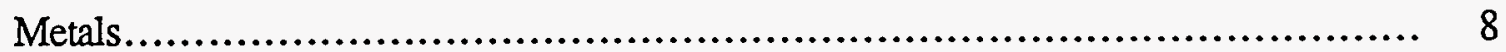

Stainless Steels................................................................. 8

Monel .................................................................... 9

Aluminum ............................................................ 10

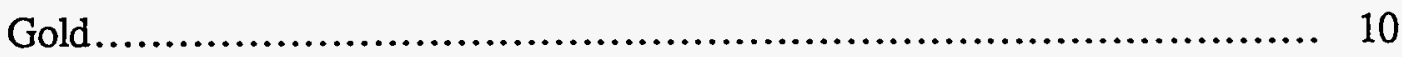

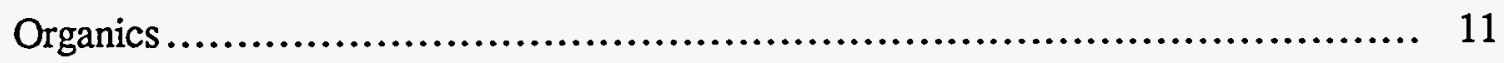

Weight Change Measurements............................................. 12

Mechanical Properties................................................. 14

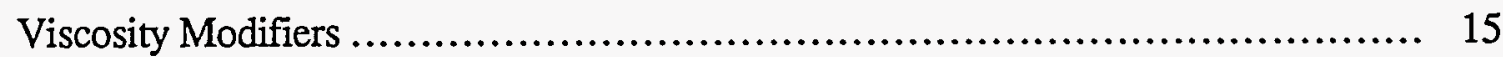

FEFO vs. Paste Exposure....................................................... 15

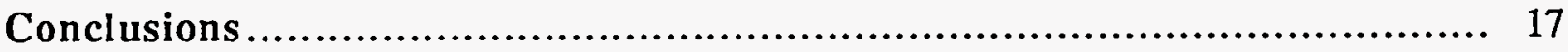

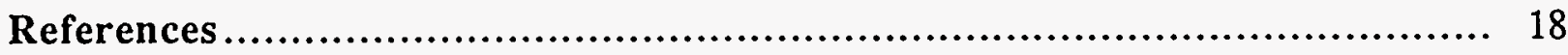




\section{A Compatibility Study Of Containment Materials In FEFO, Bis-(2-Fluoro-2,2-Dinitroethyl) Formal}

\section{Introduction}

The use of transferable paste explosives requires the qualification of containment materials for long-term exposure. Either organic or metallic materials may be used in a containment or transfer system. Metallic materials can be used for the main structural components while organic materials can be used for permeation barriers and flexible structures such as bladders, membranes, and seals. Previously, we have tested the compatibility of FM-1, one of the liquid constituents of the paste explosive, RX-08-FK ${ }^{1}$ (also called PEX) against an extensive matrix of materials. ${ }^{2}$ These liquids were found to be very aggressive towards many metallic and organic materials.

In the present study, we investigate material compatibility with a new formulation developed by Lawrence Livermore National Laboratory which is based on the solid explosive, triaminotrinitrobenzene (TATB) in the form of a fine particulate. The principal liquid constituent is: bis-(2-fluoro-2,2-dinitroethyl) formal (FEFO). There are also small additions of polymeric viscosity modifiers. The composition of this paste, designated as $\mathrm{RX}-52-\mathrm{AE}$, is :

$\begin{array}{ll}\text { TATB } & 65.0 \mathrm{wt} . \% \\ \text { FEFO } & 32.0 \mathrm{wt} . \% \\ \text { polyvinyl formal } & 1.6 \mathrm{wt} . \% \text {; } \\ \text { polycaprolactone diol } & 1.4 \mathrm{wt} . \%\end{array}$

This paste explosive is also known as TIE, Transferable Insensitive Explosive.

The majority of the work consisted of exposing materials to neat FEFO since TATB is essentially inert with regard to material corrosion and degradation. The choice of materials selected for FEFO exposure was aided by the above referenced earlier study in which many materials were found to perform unsatisfactorily when exposed to FM-1. Since one of the components of FM-1 is FEFO, few of those materials were included in the present work. The metals chosen for the present work included common structural alloys and elemental metals that the extrudable explosive might contact in its service life. The organic materials included flexible materials for use as collapsible extrusion membranes or permeation barriers, rigid engineering resins which might be used as matrices for composite structural vessels, and the polymer viscosity modifiers used in the final formulation.

Materials were exposed to the FEFO at 22 and $74^{\circ} \mathrm{C}$ for up to eight months. Changes in weight, appearance, and mechanical properties (polymers only) were measured. Surface corrosion products were characterized using electron dispersive spectroscopy, Auger analysis and X-ray photoelectron spectroscopy. The FEFO was analyzed for dissolved impurities that could have come from the exposed materials as well as changes in its chemical composition.

The effects of these exposures to FEFO are compared to material exposures in the explosive paste itself. In this way we can assess if exposure in neat FEFO was representative of an exposure to the actual paste. 


\section{Experimental}

\section{FEFO}

The FEFO (a hazard class 1.1 mass detonating, high explosive) was supplied as a 30-35 \% solution in ethyl acetate. The material was manufactured in 1971 by Rocketdyne and had been stored since in polyethylene-lined containers under uncontrolled conditions (temperature, humidity, etc.). The diluted FEFO was stripped of ethyl acetate first on a rotary evaporator then under vacuum. Pure FEFO is known to be a colorless liquid. ${ }^{3}$ Because of the age of the FEFO, its deep yellow color, and its unknown history, the FEFO was stirred with $5 \mathrm{wt}$. \% each activated carbon and neutral alumina and then filtered. The carbon filtration was repeated causing the yellow color of the FEFO to lighten. Analysis by gas chromatography/mass spectrometry (GC/MS) and GC/IR of the purified material showed a number of minor impurities including polymeric formals and numerous molecules varying slightly in their structure from FEFO. The impurities are 1-2\% of the total mass and are the subject of another study. ${ }^{4}$ Trace element analysis (ICP-MS) of the FEFO impurities showed only aluminum, silicon, and calcium present at $>1 \mathrm{ppm}$. Chlorine was not present at the detection limit of $2 \mathrm{ppm}$.

\section{Metals}

Several elemental metals were chosen for study: gold, platinum, iridium and tantalum. In addition, a number of corrosion resistant alloys were examined: Monel 400, aluminum 6061, Ta$10 \% \mathrm{~W}$, titanium-Grade 12, and two stainless steels: 304 SS and 21-6-9. Corrosion coupons measuring $6 \mathrm{~mm} \times 25 \mathrm{~mm}$ were machined from these materials. All of the metal coupons were polished to a $0.1 \mu \mathrm{m}$ finish using standard metallographic techniques. In addition, gold foils $(0.05$ $\mathrm{mm} \times 2 \mathrm{~cm} \times 5 \mathrm{~cm}$ ) were placed in exposure to maximize the surface area in contact with the FEFO so that any chemical reaction, weight change or dissolution would be clearly evident.

\section{Organics}

Coupons and mechanical test specimens of the following organic materials were chosen for exposure: polyethylene; PET polyester; Aclar 22C; a graphite epoxy composite; a vinyl ester thermoset resin, Derakane 8086 and 470-36; and five Teflons: PTFE, FEP, PFA, and Kalrez (carbon-black-filled Compound 4079 and unfilled Compound 1045). Samples of $0.25 \mathrm{~mm}$ PFA Teflon were coated on one side with either vapor deposited gold or aluminum and placed in exposure as well.

\section{Exposures}

All exposures were performed at the Mason and Hanger, Pantex Plant, Amarillo, Texas. All specimens were submerged in FEFO in borosilicate glass vials. However, duplicate sets of the gold coupons were exposed in PTFE Teflon vials. The uncapped vials were arranged in PTFE Teflon racks and placed into gold plated stainless steel canisters. The canisters were sealed with an aluminum gasket and degassed with repeated evacuation cycles to 20-50 torr refilling each time with helium. The exposures were performed under $\approx 500$ torr of helium. One canister was aged in a $74^{\circ} \mathrm{C}$ oven, the other was aged at room temperature $\left(21 \pm 2^{\circ} \mathrm{C}\right)$. At $74^{\circ} \mathrm{C}$, background offgassing from the FEFO should be minimal. 5 Periodically, samples were removed for observation and weight change analysis. Twice during the test, half of the tensile samples were removed for mechanical properties analysis. 


\section{Results}

\section{Metals}

None of the elemental metals (except for gold) showed any visible signs of interaction with FEFO at either room temperature or $74^{\circ} \mathrm{C}$. The titanium and Ta-10\%W alloys also exhibited good corrosion resistance at both temperatures. Below, we summarize specific observations regarding the interaction of FEFO with the less compatible metallic materials. Trace metal analysis of the exposed FEFO using ICP-MS failed to detect iridium, tantalum, titanium, aluminum, platinum or the elements of the stainless steels at concentrations significantly above those found in the FEFO controls. Fifty ppb of metal would have been an obvious spike above background and control concentrations.

Stainless Steels - The 304 stainless steel showed clear evidence of attack. Corrosion was evident after 55 days exposure at $74^{\circ} \mathrm{C}$, and after 125 days at room temperature. The specimens developed discrete 1-2 mm diameter areas of corrosion surrounded by unblemished metal. Extensive pitting was associated with each corrosion feature. The morphology of these corrosion features is shown in Figure 1, a scanning electron micrograph, which suggests that the pitting was crystallographic in nature. Much of the metallic corrosion products easily washed off when the specimens were rinsed clean of FEFO. Indeed, most of the corroded or attacked areas on the steel samples showed no remaining corrosion products as determined by energy dispersive $\mathrm{x}$-ray spectroscopy (EDS). Oxides have been observed in previous studies where similar steels were exposed to mixtures containing FEFO. ${ }^{2}$ In that instance, EDS spectra indicated only the presence of the principal alloying elements of stainless steel - Fe, $\mathrm{Cr}$ and $\mathrm{Ni}$ and oxygen .

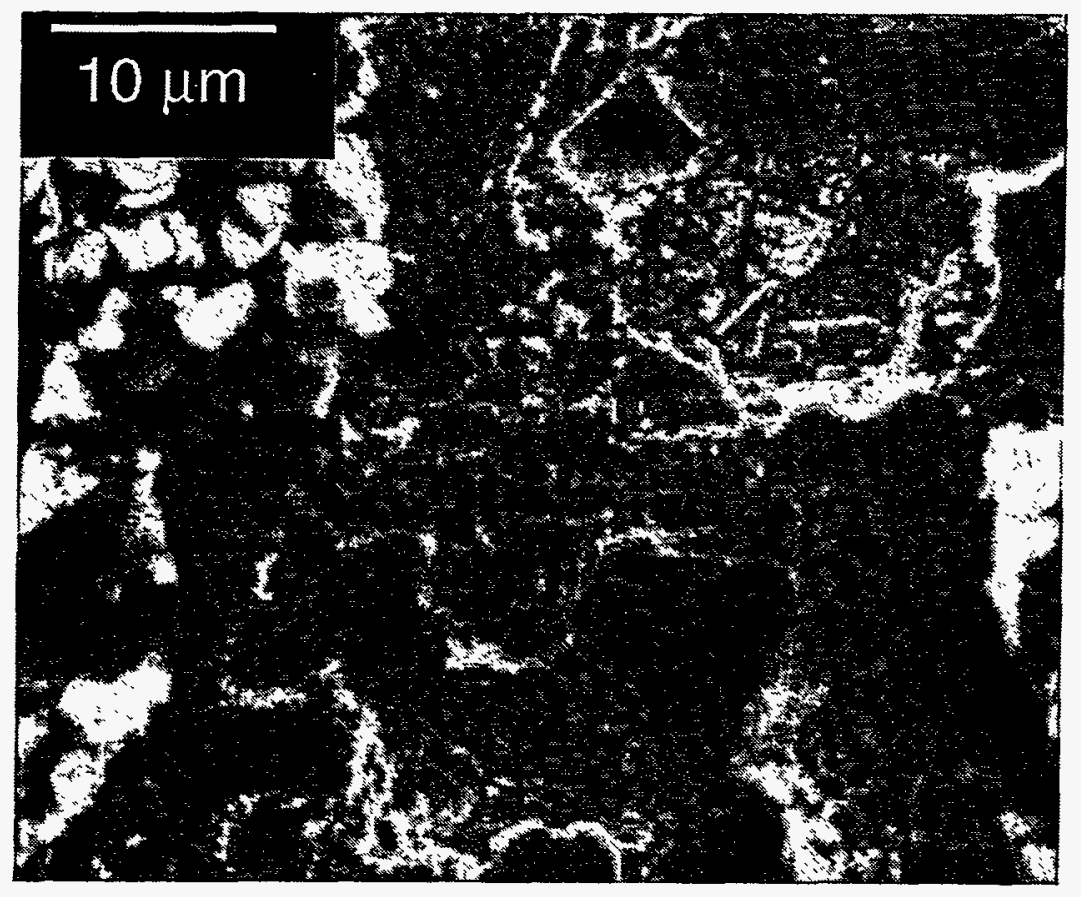

Figure 1. Scanning electron micrograph shows pitting on the polished surface of a 304 $\mathrm{SS}$ coupon after exposure to FEFO at $74^{\circ} \mathrm{C}$ for 125 days. 
In the present work, EDS revealed that there were silicon-base deposits surrounding these pits. These deposits result from the dissolution of the borosilicate vials by the FEFO. The vials became clouded and etched after months of exposure to the FEFO at $74^{\circ} \mathrm{C}$. The dissolution of the glass and its re-deposition occurred on many of the metallic coupons and was especially severe at the elevated temperature, but was also evident at room temperature.

The 21-6-9 immersed in FEFO at $74^{\circ} \mathrm{C}$ also showed obvious of attack after 55 days of exposure. The corrosion products had a rust color, which is consistent with an iron-based oxide. The coupon exposed to FEFO at room temperature was somewhat less attacked after 55 days but was clearly oxidized after 125 days of exposure.

Analysis of liquid FEFO in which these coupons were exposed (using ICP-MS) did not reveal the metallic constituents of the steel, indicating that these products were insoluble in the liquid. Though the precise corrosion mechanism and identity of the corrosion products remain unclear, the 300 series stainless steels are clearly unsuitable for use as long-term containment materials.

Monel - Monel exposed at $74^{\circ} \mathrm{C}$ exhibited visual evidence of corrosion after 125 days. An SEM micrograph (Figure 2) reveals the presence of crystallographic pitting. The attack appears to be identical to that observed in our earlier study 2 in which this pitting was preceded by the formation of surface blisters. These blisters subsequently exfoliate to form the pits shown in Figure 2.

Eventually the corrosion features spread to cover the entire surface. EDS analysis showed only the principal alloying elements (on both the blistered surfaces or within the pitted regions).

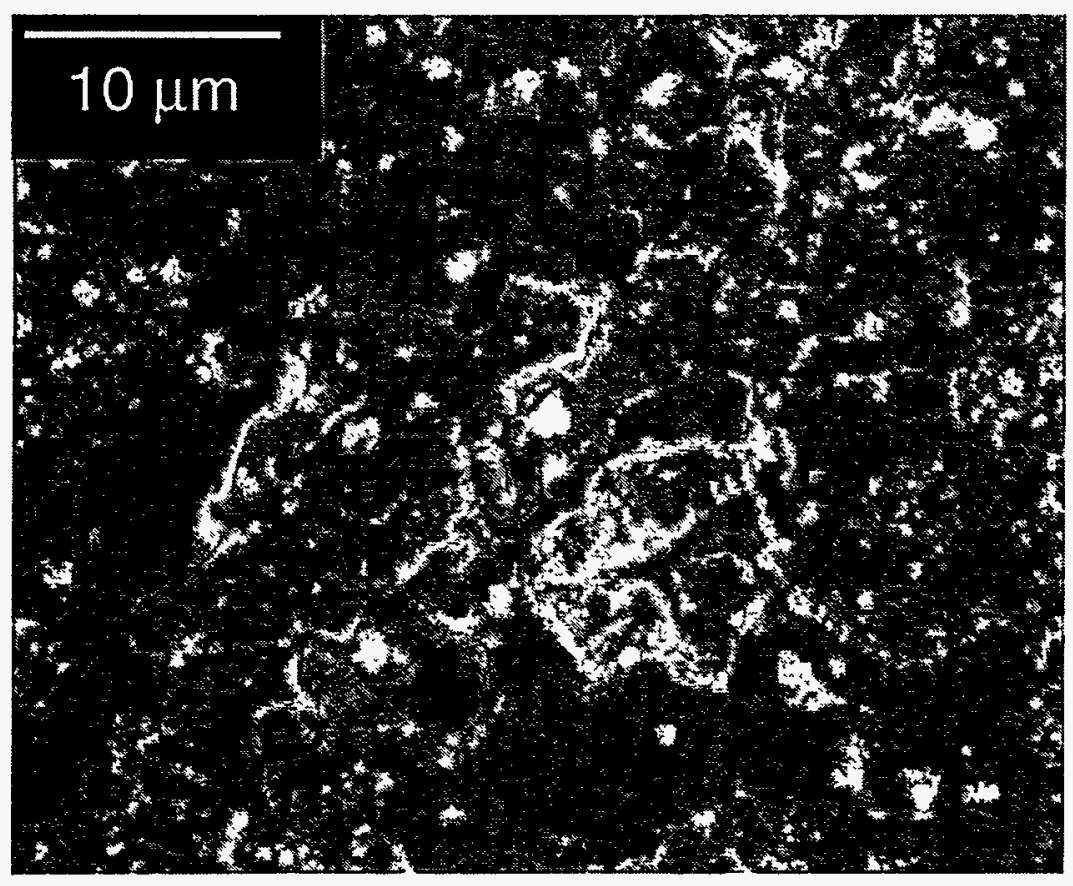

Figure 2. Scanning electron micrograph of Monel coupon reveals extensive pitting resulting from the spallation of surface blisters.

Traces of nickel and cobalt were found in some of the FEFO exposed to Monel. The metal levels were $>10$ times higher than the detection limit of these analyses (70 ppb), but not consistent from sample to sample. We attribute this to solid corrosion products yielding a heterogeneous 
distribution of particulates in the liquid. These FEFO samples were not filtered prior to ICP/MS analysis, so different amounts of solids would yield apparently different concentrations of "dissolve" metals.

Aluminum - At room temperature the most prominent response of the 6061 alloy was the formation of a silica film that completely covered the specimen surfaces. This film formed from the dissolution and re-deposition of the glass vial. The film ranged in thickness from a few tenths of a micron to approximately 4 microns. At $74^{\circ} \mathrm{C}$ the silica was less uniform and formed irregularly shaped deposits. There was some evidence of pitting after exposure at $74^{\circ} \mathrm{C}$ for 227 days. However, this pitting was minor compared to that which occurred in the stainless steels after comparable (or even much shorter) times. ICP/MS analysis of the FEFO exposed to aluminum at either temperature showed the metal present at 3-10 ppm, the same levels as found in the control samples of FEFO. Recent results, from as yet unpublished work, demonstrate that aluminum alloys are not compatible with FEFO and other similar energetic liquids. ${ }^{6}$

Gold - The gold specimens developed an obvious, uneven tarnish film after 55 days of exposure at $74^{\circ} \mathrm{C}$ and after 159 days at room temperature. The gold foil exhibited a weight change over time that coincided with the formation of this tarnish film, see Figure 3 . The reactions between FEFO and gold have been studied in detail elsewhere. ${ }^{7}$ In that work, XPS analysis of gold exposed under

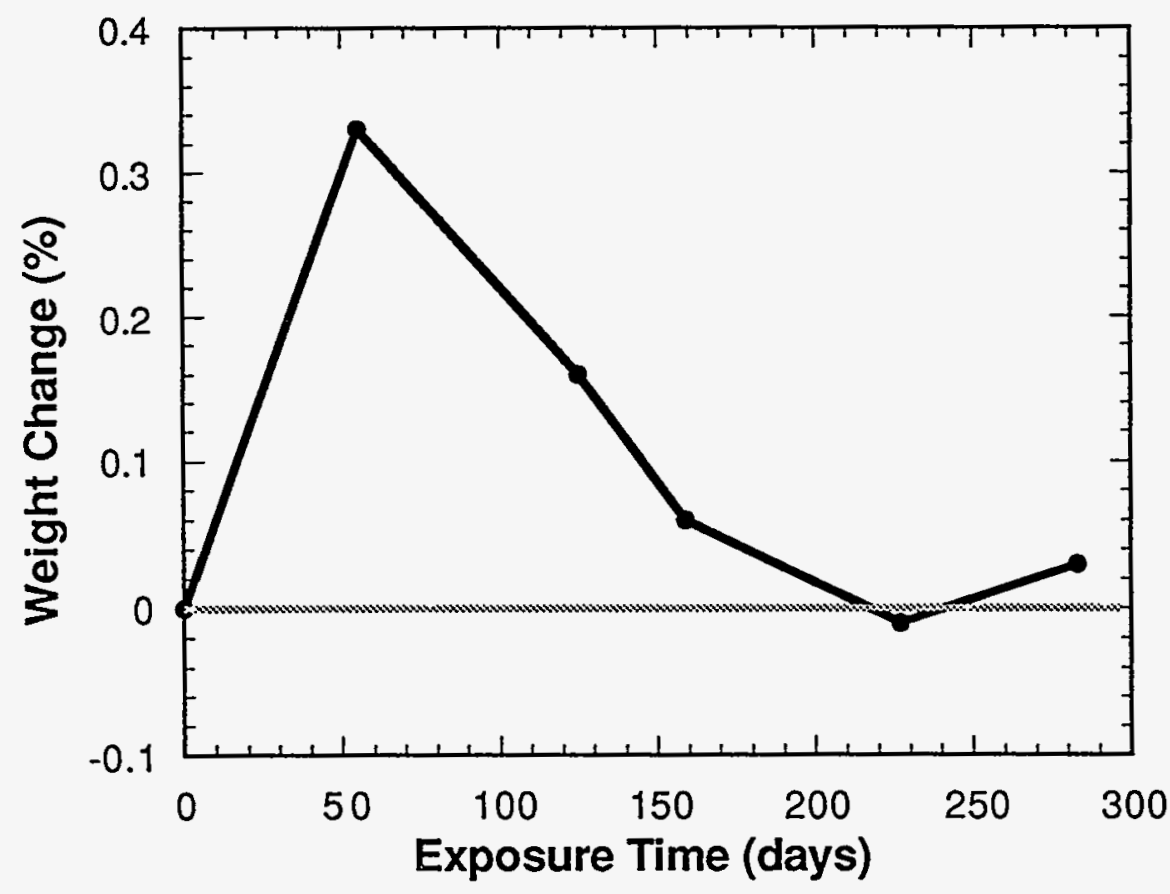

Figure 3. Gold weight change vs. time. Initial weight change correlates with the appearance of a tarnish film. 
similar conditions reveals that this surface film results from the formation of gold cyanide. Although the extent of these reactions appears to be small, they are of great interest because of the usual inert nature of gold when exposed to aggressive media. With further study, gold may be found suitable for use as an electroplated barrier in conjunction with conventional, but FEFOincompatible alloys. These reactions have been subject to a more detailed study. ${ }^{8}$

The FEFO exposed to the gold was analyzed by ICP/MS. Less than $0.5 \mathrm{ppm}$ of gold was found in FEFO from each temperature. Gold was not found at the detection limit of $0.01 \mathrm{ppm}$ in any of the control FEFO samples. We assume that the dissolved gold represents gold cyanide dissolved from the tarnish film on the metal.

\section{Organics}

Vials containing only FEFO were placed in exposure along with the material coupons. After 227 days, the room temperature control was visually unchanged while the $\mathrm{FEFO}$ at $74^{\circ} \mathrm{C}$ yellowed slightly. The identity and distribution of the trace impurities changed in both the FEFO controls and the FEFO exposed to metals. New impurities appeared in the high-temperature FEFO control by the end of the study. These impurities were minor (total $<2 \%$ ) and most of them resulted from the loss of $\mathrm{NO}$ or $\mathrm{NO}_{2}$ molecules from FEFO. These reactions are discussed in more detail elsewhere. 9

The various organic materials showed different degrees of degradation after exposure. None of the Teflon or polyester samples showed any visible changes after exposure at either temperature. The graphite epoxy samples also appeared unchanged. The FEFO exposed to the graphite epoxy sample at $74^{\circ} \mathrm{C}$ was slightly more yellow than the control. Though the color changes of the samples and surrounding FEFO indicate some reactions were occurring, no significant differences in the chemical composition of the FEFO were noted by either NMR or GC/MS.

The polyethylene and Aclar 22C samples exposed at room temperature appeared unchanged, while the ones aged at $74^{\circ} \mathrm{C}$ yellowed after 227 days. Larger Aclar $22 \mathrm{C}$ samples used for weight change measurements were rolled to fit into the vials. These samples developed stress cracks perpendicular to the curl. The two Derakane formulations, $470-36$ and 8084 , both showed some effects upon exposure that were accelerated at the higher temperature. The 8084 formulation developed slight surface crazing after 159 days. The FEFO surrounding the 8084 darkened to an orange color. The 470-36 formulation showed similar surface crazing and deep cracks. The FEFO exposed to the $470-36$ became dark brown.

PFA Teflon films were sputter coated with $100 \mathrm{~nm}$ thick layers of aluminum or gold and then exposed to FEFO. The PFA film was a commercially available material that had been corona discharge treated to promote adhesion. The coating was opaque and was adherent as measured by standard tape tests. Upon exposure to FEFO for 68 days, these laminates degraded, especially at $74^{\circ} \mathrm{C}$. The aluminum had sloughed off the plastic in places and the remainder was easily wiped off. The gold laminate showed small areas where the gold was gone and a uniform thinning of the metal to a thinner, transparent layer. This effect was more apparent at the edges, suggesting that the FEFO also reacted with the gold by infiltrating the plastic/metal interface. Again, the metal could be easily wiped from the Teflon. The clear failure of these laminates precludes their use in future engineered structures. 
Weight Change Measurements - Weight change of the polymers as a function of time was examined as a quantitative measure of the interaction between the organic materials and the liquid. Figure 4 shows the results of these measurements for coupons exposed at room temperature.

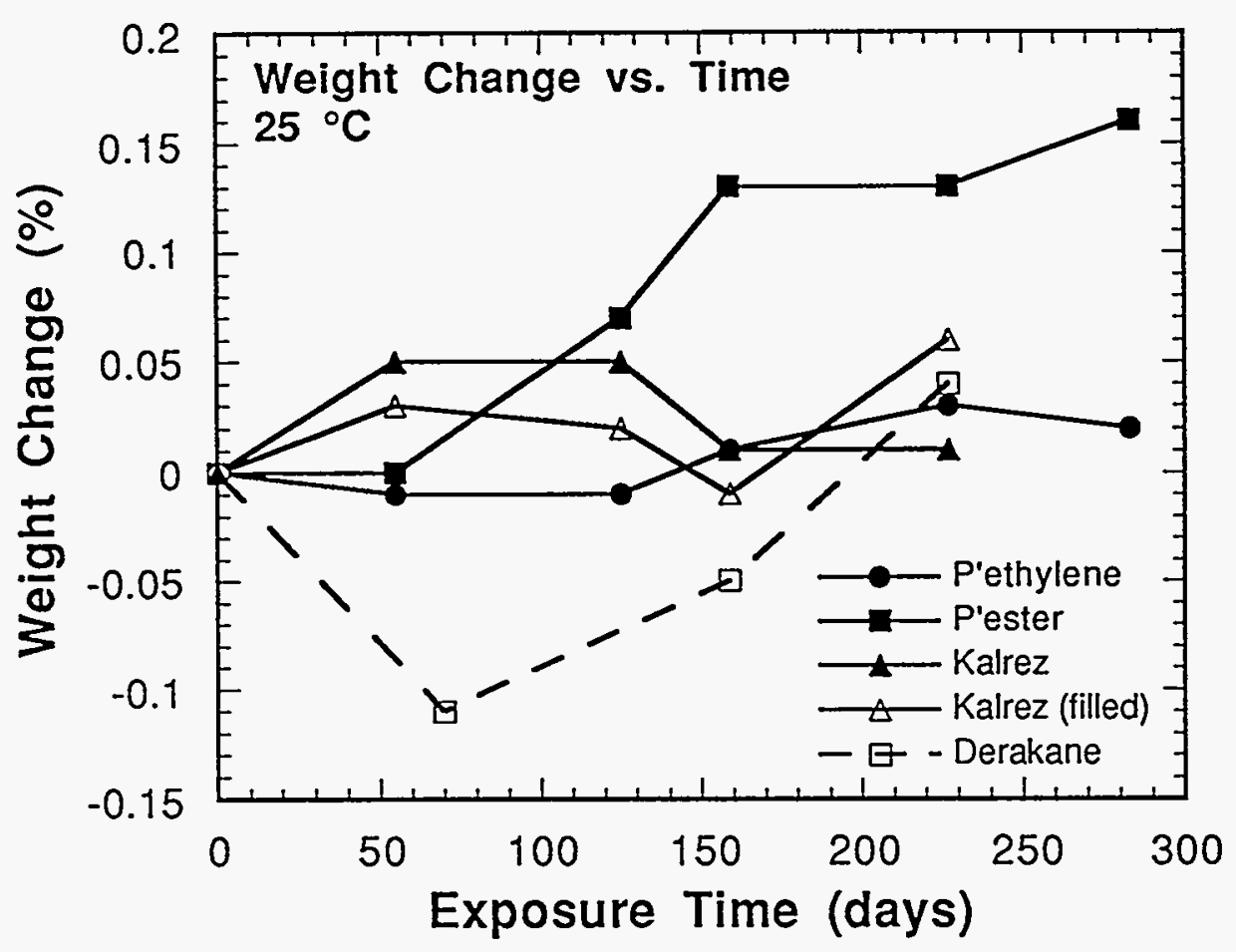

Figure 4. Weight change measurements for coupons exposed at room temperature.

Due to the limitations of the balance used, weight changes of less than $0.05 \%$ were not considered reliable. Some of the materials that exhibited weight changes less that this threshold are not shown in the figure. In general, the weight changes at room temperature were quite small and are likely to be of no consequence. Only the polyester exhibited systematic increases in weight above the resolution of the balance. After 283 days of exposure the weight change of the polyester was $\approx 0.15 \%$.

Figure 5 shows the results of the weight change measurements for coupons exposed at $74^{\circ} \mathrm{C}$. Here, the weight changes were typically greater than at room temperature, but still small for many of the materials. Again, the largest weight change observed was for the polyester, which exhibited a $5 \%$ increase after 283 days of exposure. Further, the weight change of the polyester exhibited a parabolic time dependence suggesting a diffusion controlled, self-limiting process. Permeation parameters can be calculated for processes such as these.

The mathematics of calculating the permeability and diffusivity from diffusion into a planar sheet are derived in the literature. ${ }^{10,11}$ These calculations have been applied to the diffusion of energetic liquids, ${ }^{12}$ water vapor, ${ }^{13}$ and other solvents ${ }^{14,15}$ in polymers. Assuming diffusivity is independent of concentration, for a planar sheet of thickness $(\mathrm{h})$, the diffusivity is calculated from the slope (q) of the initial portion of an uptake plot (mol permeant/g polymer vs. time ${ }^{1 / 2}$ ):

$$
\mathrm{D}=\pi\left(\mathrm{hq} / 4 \mathrm{~K}_{\mathrm{eq}}\right)^{2}
$$




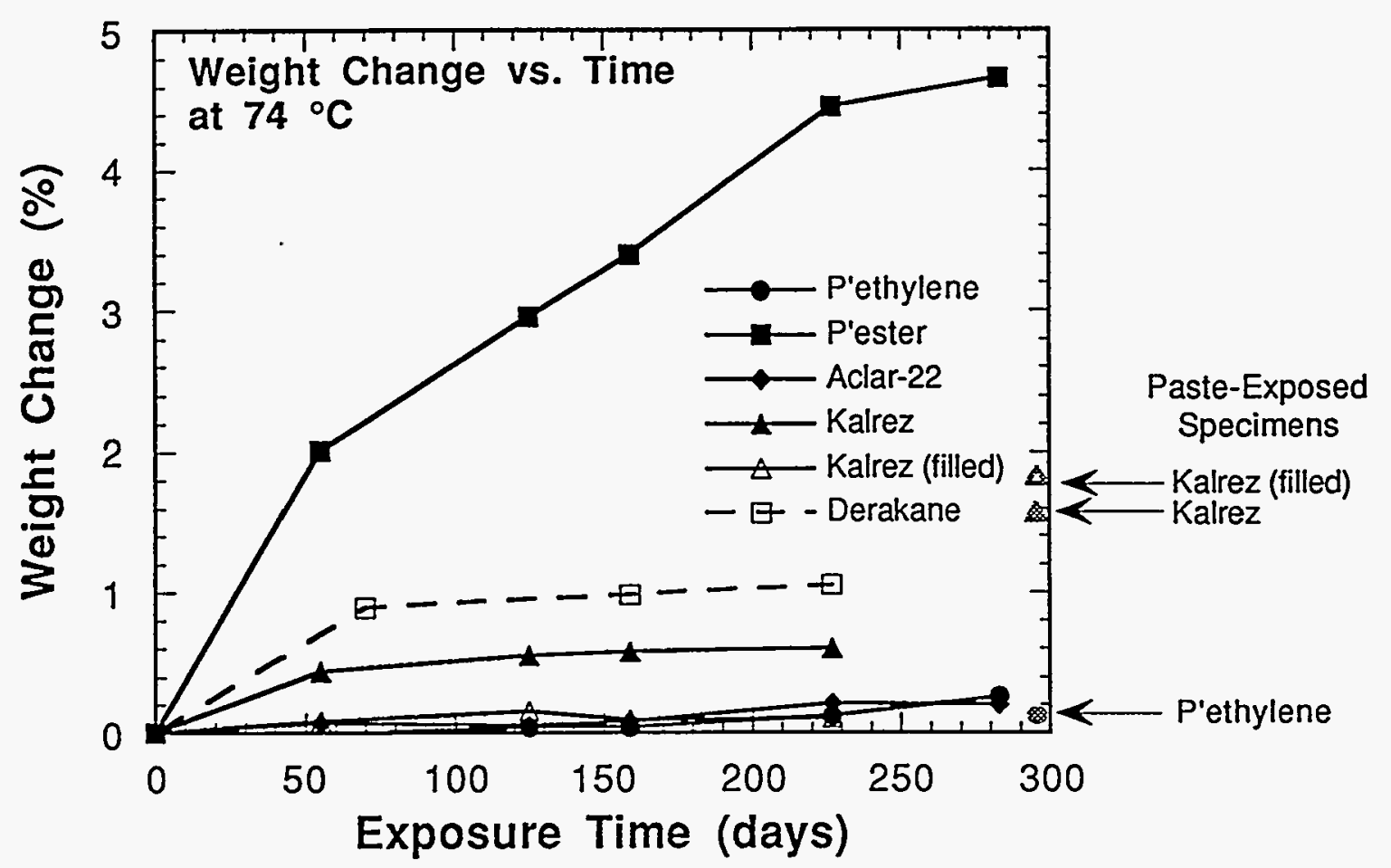

Figure 5. Weight change measurements for coupons exposed at $74^{\circ} \mathrm{C}$ to $\mathrm{FEFO}$ and to RX-52-AE.

Within the parameters of these experiments, the permeability in $\mathrm{mol} \mathrm{s}^{-1} \mathrm{~m}^{-1}$ is the product of diffusivity in $\mathrm{m}^{2} / \mathrm{s}$, the equilibrium solubility in moles of solvent/gram polymer, and the density $(\rho)$ of the membrane in gram polymer $/ \mathrm{m}^{3}$.

$$
\mathrm{P}=\mathrm{D} \mathrm{K}_{\mathrm{eq}} \rho
$$

Some of the most rapid examples of permeation by FEFO were calculated and are tabulated in Table I. Polyester was the only material where the room temperature solubility of FEFO in the polymer was sufficient to accurately calculate permeation parameters. The permeation of FEFO through barrier membranes is the subject of a separate study. ${ }^{11}$ These results demonstrate that weight change measurements are not an obvious indicator of the magnitude of diffusivity and permeability.

Table I: Some Permeation Parameters for FEFO

\begin{tabular}{|c|c|c|}
\hline Polymer & $\begin{array}{c}\text { Diffusivity } \\
\left(\mathrm{m}^{2} \mathrm{~s}^{-1}\right)\end{array}$ & $\begin{array}{c}\text { Permeability } \\
\left(\mathrm{mol} \mathrm{s}^{-1} \mathrm{~m}^{-1} \mathrm{~atm}^{-1}\right)\end{array}$ \\
\hline \hline Polyester $\left(22^{\circ} \mathrm{C}\right)$ & $2.5 \times 10^{-16}$ & $1.9 \times 10^{-15}$ \\
\hline Polyester $\left(74^{\circ} \mathrm{C}\right)$ & $8.5 \times 10^{-16}$ & $1.8 \times 10^{-13}$ \\
\hline Kalrez (Filled, $\left.74^{\circ} \mathrm{C}\right)$ & $1.8 \times 10^{-15}$ & $5.8 \times 10^{-14}$ \\
\hline Derakane $\left(74^{\circ} \mathrm{C}\right)$ & $1.0 \times 10^{-14}$ & $3.4 \times 10^{-13}$ \\
\hline
\end{tabular}


For Kalrez, the unfilled specimens showed markedly larger weight change than the carbon filled material (Compound 4079). While it has inherently poorer mechanical properties than Compound 4079 , the unfilled Kalrez is typically chosen for its superior performance in severely oxidizing environments. Insofar as weight change is concerned, both Kalrez formulations appear adequate for the present application. While measurable weight changes are not necessarily indicative of fundamental incompatibility, they suggest that further assessments may be necessary before a material can be qualified for prolonged exposure.

Mechanical Properties - Mechanical properties were measured for the organic materials after 125 and 227 days of exposure. Duplicate or triplicate tests were run for each material. Several materials showed dramatic changes in ductility with exposure to FEFO. An example of this is shown in Figure 6 which compares the tensile behavior of Aclar 22C exposed at room temperature and $74^{\circ} \mathrm{C}$ to the baseline behavior of unexposed material.

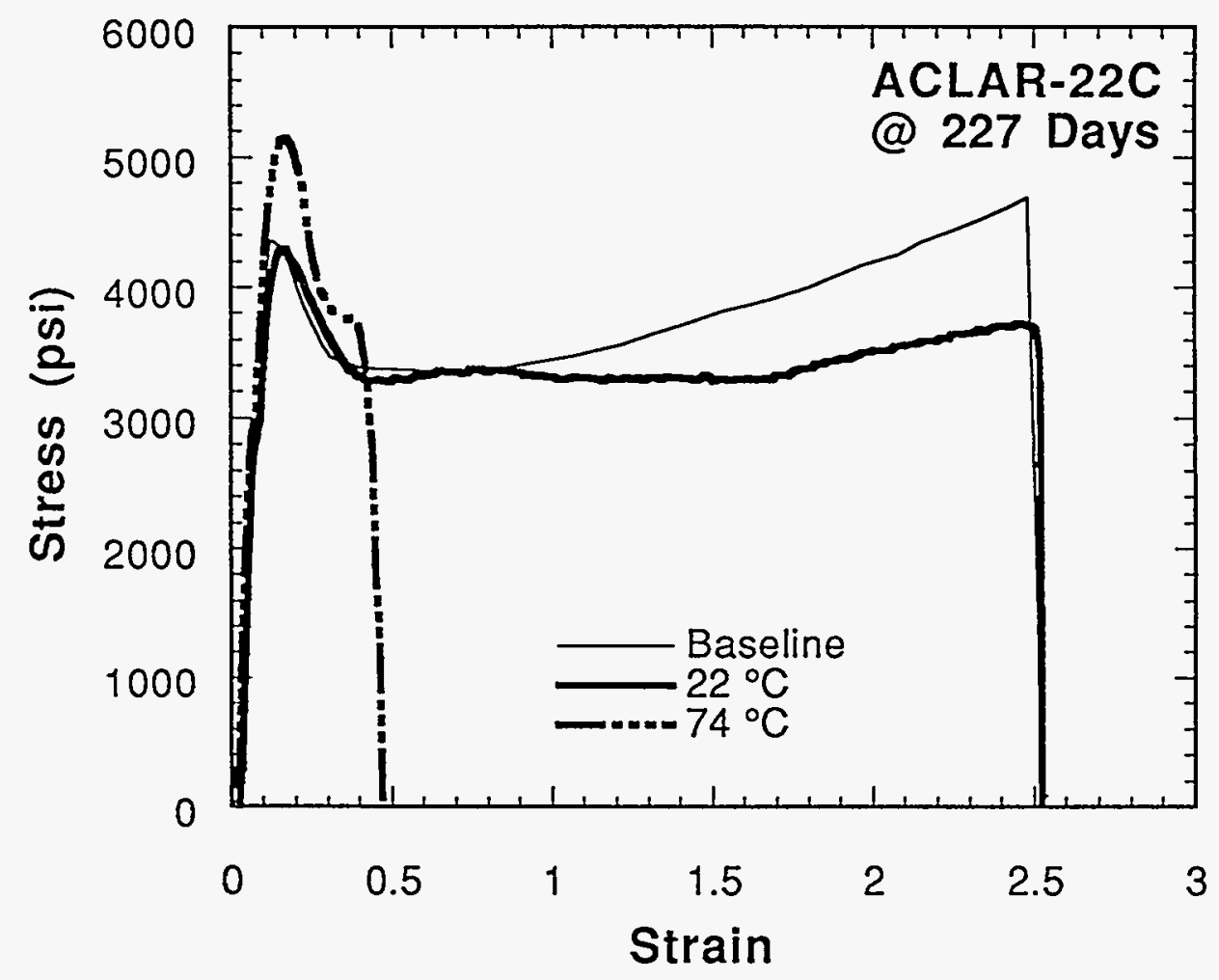

Figure 6. Comparison of the tensile behavior of FEFO exposed Aclar-22C to the baseline behavior of unexposed material.

Figure 7 shows the change in fracture strain as a percentage of baseline ductility (for unexposed material) after the longest exposure period. Because of the limited number of specimens available for repeat testing, changes of less than $20 \%$ should not be considered significant. Although PTFE exhibited no significant weight change over the course of the experiment, the mechanical tests revealed a measurable increase in ductility suggesting that the small amount of dissolved FEFO plasticizes the polymer matrix. Only the polyester and Aclar exhibited significant ductility losses under these exposure conditions. Neither the Derakane resins nor the graphite-epoxy specimens are shown since their minimal ductility makes the kind of comparisons presented in Figure 7 unreliable. None of those materials exhibited any measurable changes in ductility or strength. 


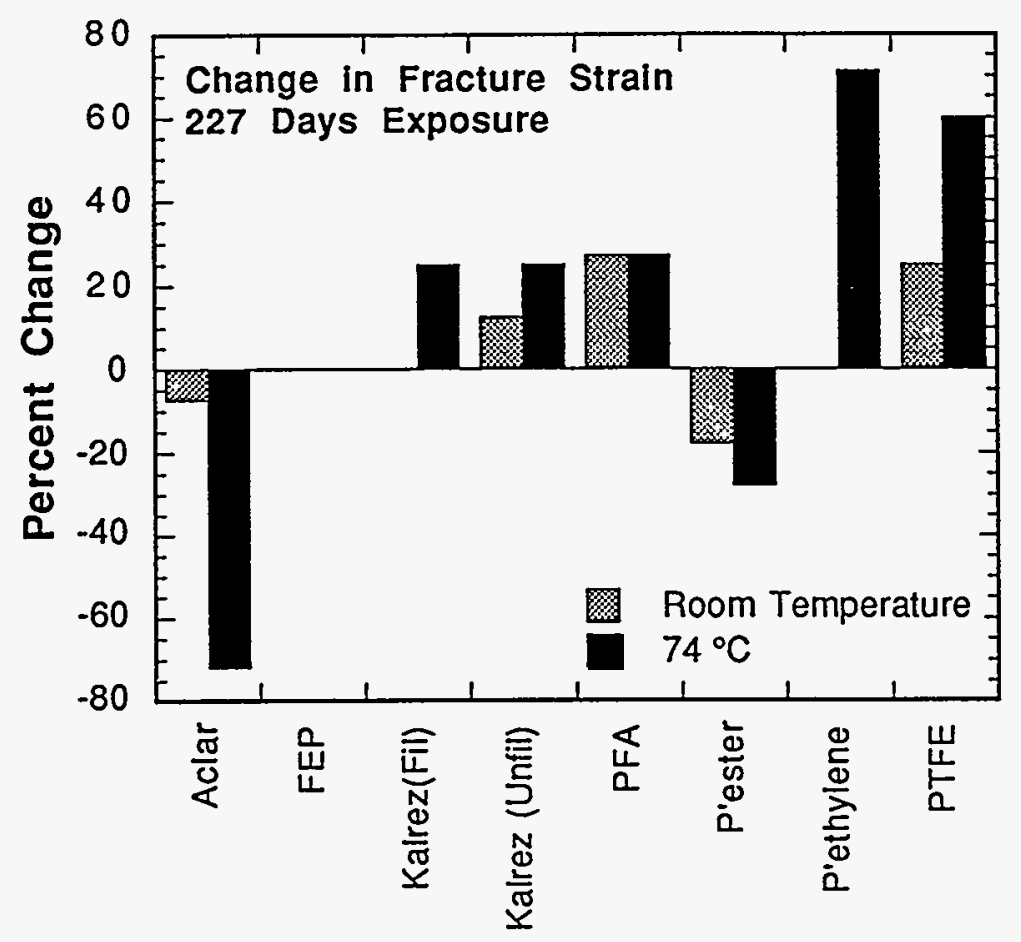

Figure 7. Change in fracture strain of organic specimens exposed at $74^{\circ} \mathrm{C}$ to FEFO for 227 days.

\section{Viscosity Modifiers}

Two polymers are dissolved in FEFO to control viscosity in RX-52-AE. Their compatibility was tested by aging them each with FEFO in deuterated $1,1,2,2$-tetrachloroethane solution at $74^{\circ} \mathrm{C}$ for 250 days. Control samples without FEFO were aged under the same conditions. The samples were removed periodically from the oven and their GC/MS, ${ }^{1} \mathrm{H}$ and ${ }^{13} \mathrm{C}$ NMR spectra were recorded. The polycaprolactone diol (Tone 240, Union Carbide) showed slightly different NMR spectra with increasing aging time. Tone 240 is a diol initiated polycaprolactone that can rearrange under acid or base catalysis. GC/MS traces of the aged mixture revealed no new volatile products of consequence $\left(\leq 250^{\circ} \mathrm{C}\right)$ We assume that the changes involve the terminal hydroxyls reacting inter- or intramolecularly with other ester groups. These reactions change the molecular weight distribution of the polycaprolactone without seriously degrading the performance of the polymer. Though its exact structure may change substantially, as long as the polycaprolactone remains a polymer, it should still serve to thicken the FEFO in which it is dissolved. The polyvinylformal (Formvar 5/95E, Monsanto) showed almost no indication of any reaction with FEFO by NMR or $\mathrm{GC} / \mathrm{MS}$ and should function in its role as a thickening agent over prolonged periods.

FEFO vs. Paste Exposure - The effect of exposure to FEFO was compared to exposure to the explosive paste (TIE) itself (RX-52-AE). This was done to determine if exposure to the neat liquid constituted a gross over test of compatibility relative to the paste formulation. The right hand ordinate of Figure 5 shows the weight change after $\approx 300$ days of exposure of polyethylene and both Kalrez materials to RX-52-AE. Obvious differences in weight changes were observed relative to FEFO exposure, but the magnitude of the changes remains small. 
Figure 8 is another such comparison, showing the mechanical properties of PFA specimens exposed to FEFO and RX-52-AE as well as unexposed baseline specimens. It is clear that both of the exposed specimens show the same changes in mechanical properties relative to the as-received material and that insofar as mechanical properties are concerned, FEFO-only exposures are acceptable for characterizing material response to the complete paste formulation.

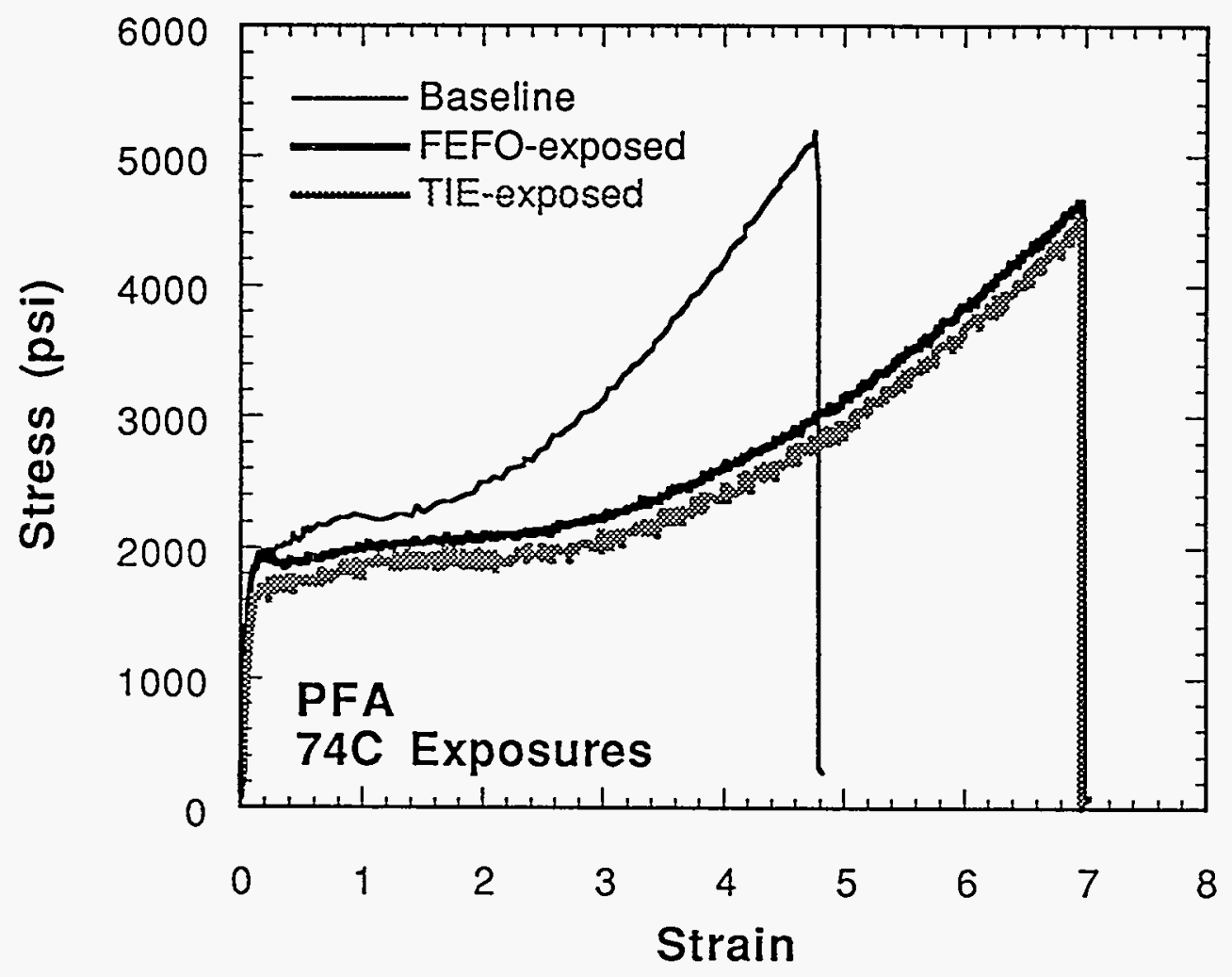

Figure 8. Comparison of mechanical properties of PFA specimens exposed to FEFO and RX-52-AE (TIE) as well as unexposed baseline specimens. 


\section{Conclusions}

The stainless steels did not exhibit adequate compatibility for long-term exposure to a FEFO-based paste explosive. Oxidation appears to be the principal mechanism by which chemical attack occurs. Monel 400 also proved to be an unacceptable containment material, exhibiting a tendency to blister and pit while exposed to FEFO. The aluminum alloy showed some evidence of minor pitting at $74^{\circ} \mathrm{C}$. Although the gold showed some evidence of interaction with the liquid, the level of interaction with FEFO may not preclude it from use as an electroplated permeation barrier. The rest of the alloys and elemental metals showed no evidence of degradation after exposure to FEFO at either temperature.

The results presented here identify potentially useful organic materials such as Kalrez, FEP, and PFA. None of these materials showed any visual, physical, or mechanical property changes after exposure. For ambient temperature applications, polyethylene and polyester may be adequate. The minimal reaction between the viscosity modifiers and FEFO suggests that $\mathrm{RX}-52-\mathrm{AE}$ will not degrade over time. While the differences in material response to FEFO and paste exposures were typically small, the weight change results suggest that there can be measurable differences and future studies must include paste exposures for final qualification of materials.

At this writing, additional tests are in progress that address the issue of material compatibility for all of the liquid constituents of RX-08-FK. Many of the materials described here are included in this test matrix. 


\section{References}

1. E. von Holtz, K Scribner, R. Whipple, J. Carley, "Paste Extrudable Explosives. Their History and Their Current Status," Lawrence Livermore National Laboratory Report No. UCRL-LR-110156, April 30, 1992.

2. S. H. Goods, T. J. Shepodd, B. E. Mills, P. Foster, "A Material Compatibility Study in FM-1, a Liquid Component of a Paste Extrudable Explosive, RX-08-FK," Sandia National Laboratories Report No. SAND93-8237, UC-704, September 1993.

3. Y. Oyumi, T. B. Brill, Propellants, Explosives, Pyrotechnics, 1986, 11, 35-39.

4. W. E. Moddeman, J. C. Birkbeck, P. A. Foster, S. H. Goods, T. J. Shepodd, Surface Reactions of Liquid Explosives with Gold for the Transferable Insensitive Explosive Program. Presented at the 19th DOE Compatibility, Aging, and Service Life Conference, Los Alamos, New Mexico, September 28-30, 1994.

5. K. F. Mueller, R. H. Renner, W. H. Gilligan, H. G. Adolph, M. J. Kamlet, Combustion and Flame, 1983, 50, 341-349.

6. T. Shepodd, S. Goods, P. Foster, A Compatibility Study of Containment Materials in FEFO. Presented at the 19th DOE Compatibility, Aging, and Service Life Conference, Los Alamos, New Mexico, September 28-30, 1994.

7. W. Moddeman, B. Sims, P. Foster, S. Goods, T. Shepodd, Surface Spectroscopic Examinations of Gold and Aluminum Aged in FM-1/EDNP/EG Liquid Carrier for the PEX Program. Presented at the 18th DOE Compatibility, Aging and Service Life Conference, Savannah River Technology Center, Aiken, South Carolina, April 20-22, 1993.

8. W. Moddeman, B. Sims, P. Foster, S. Goods, T. Shepodd, J. C. Birkbeck, Surface Analytical Studies on the Reactions of Platinum Group Metals with FEFO an Energetic Binder. Proceedings of the International Symposium on Energetic Materials Technology. Sponsor: American Defense Preparedness Association, Orlando, Florida, March 21-24, 1994.

9. W. E. Moddeman, J. C. Birkbeck, S. B. Malcolm, S. H. Goods, T. J. Shepodd, GC/MS/FTIR Studies of Unaged FEFO and of FEFO Aged in the Presence of Gold. Presented at the 19th DOE Compatibility, Aging, and Service Life Conference, Los Alamos, New Mexico, September 27-30, 1994.

10. J. Crank, The Mathematics of Diffusion, Claredon, Oxford, 1975, Chapter 4.

11. J. Comyn, Polymer Permeability, Elsevier, London, 1985.

12. T. J. Shepodd, A. R. Daniel, G. B. Buffleben, P. Foster, "The Permeation of bis(2-fluoro2,2-dinitroethyl) formal (FEFO), Ethyl 4,4-dinitropentanoate (EDNP), Ethyl 4nitropentanoate (ENP), and 1,2,4-Trichlorobenzine (TCB) Through Barrier Membranes," Sandia National Laboratory Report No. SAND94-8239, 1994.

13. K. T. Gillen, P. F. Green, "Moisture Permeation of Environmental Seals Used in Weapons," Sandia National Laboratory Report No. SAND92-2651, UC-704, February 1993.

14. T. M. Aminabhavi, R. S. Kinnavar, Polymer, 1993, 34, 1006-1018.

15. S. B. Harogoppad, T. M. Aminabhavi, Polymer, 1991, 32, 870-876. 


\section{INITIAL DISTRIBUTION}

Mason \& Hanger-Silas Mason Co., Inc.

Pantex Plant

Explosives Technology Division

Attn: Pat Foster (5)

Bill Moddeman (5)

Jan Birkbeck

Cliff Schaeffer

Arnie Duncan

Bill Faubian

P.O. Box 30020

Amarillo, TX 79177

Bill Bookless, LLNL, L-035

Mark Hoffman, LLNL, L-282

Randy Simpson, LLNL, L-282

Bill Tao, LLNL, L-282
MS 0427 V. O. Willan, 5103 (2)
MS 9001 J. C. Crawford
MS 9006
MS 9005
MS 9004
MS 9037
MS 9054
MS 9105
MS 9002
MS 9901
MS 9141
MS 9003
MS 9032
MS 9053
MS 9055
MS 9055
MS 9401
MS 9402
MS 9042
MS 9043
MS 9043
MS 9042
MS 9044
MS 9402
MS 9402
MS 9402
MS 9403
$\begin{array}{ll}\text { Attn: } & \text { E. E. Ives, } 5200 \\ \text { J. B. Wright, } 5300\end{array}$
M. E. John, 8100
R. J. Detry, 8200
W. J. McLean, 8300
L. A. Hiles, 8400
P. N. Smith, 8500
L. A. West, 8600
M. Dyer, 8800
D. L. Crawford, 8900
C. T. Oien, 5361
C. M. Hartwig, 8366
L. Minier, 8353
R. Behrens, 8353
R. C. Wayne, 8700
Attn: G. J. Thomas, 8715
G. A. Benedetti, 8741
P. E. Nielan, 8742
M. L. Callabresi, 8743
R. J. Kee, 8745
W. A. Kawahara, 8746
J. R. Spingarn, 8714
M. W. Perra, 8713
S. H. Goods, 8714 (5)
MS 9403
MS 9404
MS 9404
MS 9404
J. E. Costa, 8711
M. I. Baskes, 8712
A. R. Daniel, 8713
B. E. Mills, 8713
MS 9404
D. L. Miller, 8713
MS 9404
G. M. Buffleben, 8713
MS 9404
J. C. F. Wang, 8713
J. M. Hruby, 8716 
MS 9404 L. A. Domeier, 8713

MS 9404 R. W. Bradshaw, 8716

MS 9404 T. J. Shepodd, 8713 (5)

MS 9405 D. L. Lindner, 5605

MS 9406 D. Kim, 8412

MS 9406 L. Derickson, 8412

MS 9407 E. T. Cull, 8415

MS 9022 Mail Distribution, 8533-1, OSTI (10)

MS 9022 Mail Team Distribution, 8533-1

MS 0899 Technical Library Department, 13414 (4)

MS 9018 Central Technical Files, 8523-2 (3) 